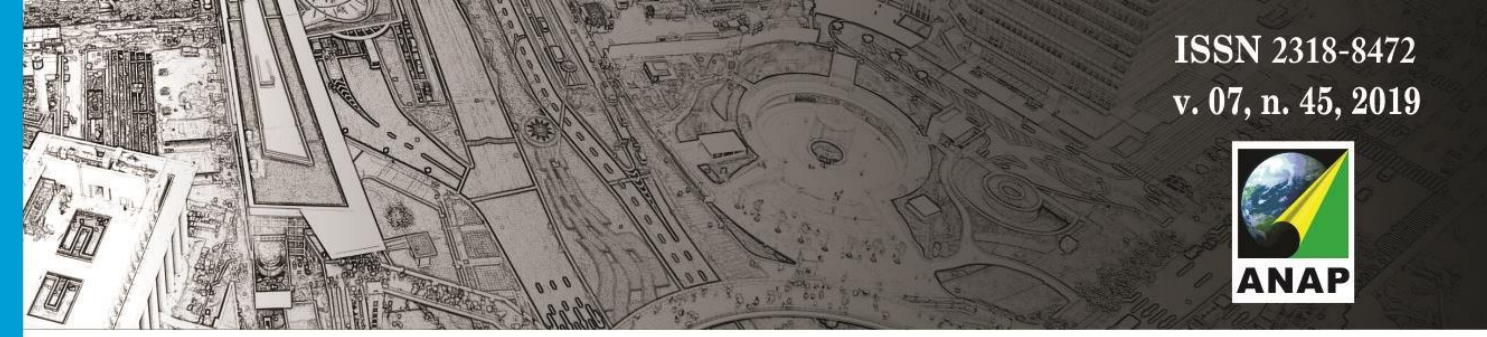

Revista Nacional de

Gerenciamento de Cidades

\title{
Resiliência $=$ Vulnerabilidade + Adaptação Análise da cidade de Pereira Barreto/SP
}

\author{
Resilience $=$ Vulnerability + Adaptation \\ Analysis of the city of Pereira Barreto / SP
}

Resiliencia $=$ Vulnerabilidad + Adaptación

Análisis de la ciudad de Pereira Barreto / SP

\section{Ariadine Fernandes Collpy Bruno \\ Mestranda, PPGARQ, UNESP \\ arqurbariadine@gmail.com}

Norma Regina Truppel Constantino

Professora Doutora, PPGARQ, UNESP

nconst@faac.unesp.br 


\section{Revista Nacional de}

Gerenciamento de Cidades

\section{1- INTRODUÇÃO}

Resiliência segundo Pisani \& Lima (2017) significa voltar ao estado normal, e é um termo oriundo do latim resiliens. Resiliência possui diversos significados para a área da psicologia, administração, ecologia e física. Pode ser explicada como a capacidade de voltar ao seu estado natural, principalmente após alguma situação crítica e fora do comum.

Podemos perceber, de acordo com essa afirmação, que a resiliência acontece quando uma ou mais pessoas, no caso da resiliência humana, são expostas a situações críticas, ficando vulneráveis e necessitando de uma adaptação para prosseguirem. Existem tipos de vulnerabilidade que serão tratados como social ou ambiental, e as mesmas resultarão em uma pseudo "adaptação", pois a adaptação real é composta por um conjunto das modificações através das quais um ser se ajusta às condições do meio ambiente, tentando se acomodar.O pesquisador Douglas Gallo (2017) entende o binômio vulnerabilidade-resiliência como conceito integrador e multidimensional, e busca reconhecer seu sentido e importância numa discussão de promoção da qualidade de vida urbana.

A cidade de Pereira Barreto, em 1927, era um local que não apresentava a mínima estrutura, onde tudo necessitava ser construído a partir da chegada de colonos, vindos do Japão. Em toda acidade, tudo seria construído a partir das memórias que as famílias, que continuavam chegando do outro lado do mundo, traziam em suas bagagens.

Totalmente vulneráveis à terra nova e com expectativas de adaptação, devido ao que era oferecido a estas famílias, eles iam chegando e escolhendo o local onde fixariam residência, pois, no Japão eles compravam um título de donos de uma porção de terra, mas, só saberiam qual seria essa "porção", quando chegassem ao local. Conforme esclarecimentos de antigos moradores, havia sido prometido, que eles seriam donos da terra em um país livre "de um Imperador tirano e com seu trabalho nessa terra promissora, tinham a certeza esperançosa de enriquecimento", pois haviam comprado uma terra que era "tão fértil, que tinha o valor de ouro em pó". ${ }^{1}$

De acordo com Buss (2000), é possível agrupar duas diferentes conceituações sobre as transformações físicas e comportamentais desses imigrantes. A primeira consiste em atividades dirigidas à transformação dos comportamentos dos indivíduos, focando nos seus estilos de vida, ambientes e territórios onde se encontram, considerando a sua cultura particular e, por conseqüência, as ações se dariam no nível pessoal. A segunda vertente sustenta-se no entendimento de que a saúde é produto de um amplo espectro de fatores relacionados à qualidade de vida, incluindo aí a alimentação e nutrição, habitação e saneamento, condições de trabalho e oportunidades educacionais, ambiente físico e apoio social, além dos cuidados com a saúde de modo geral, exigindo ações mais globais e abrangentes.

\footnotetext{
1 Informações obtidas no depoimento de Sergio Massuda, presidente do Museu de Cultura Japonesa de Pereira Barreto. Estas informações foram consultadas por ele, nos registros de relatos dos imigrantes de 1938.
} 




Este ensaio, apoiado em dados e fatos históricos, apresenta tanto a vulnerabilidade da população e da paisagem, quanto a adaptação a que as mesmas foram "forçadas" a aceitar de maneira resiliente, para que a cidade continuasse a existir. Essa população de imigrantes havia se desfeito de tudo no Japão para iniciar vida nova em solo brasileiro.

\section{2- FORMAÇÃO DA CIDADE DE PEREIRA BARRETO/SP}

A cidade se formou a partir da fazenda Tietê. O proprietário da fazenda Tietê, Coronel Jonas Alves de Mello, que além de lotear a gleba em lotes de 10alqueires, comercializou estes lotes com a BRATAC- Sociedade Colonizadora do Brasil. A empresa ficou responsável por vender os lotes para 1500 famílias japonesas, a partir de 1927. (Figura 1)

Figura 1. Projeto de colonização da gleba Fazenda Araçatuba que foi dividido em 10 alqueires Paulistas e comercializado no Japão pela Cia Colonizadora BRATAC, 1927.

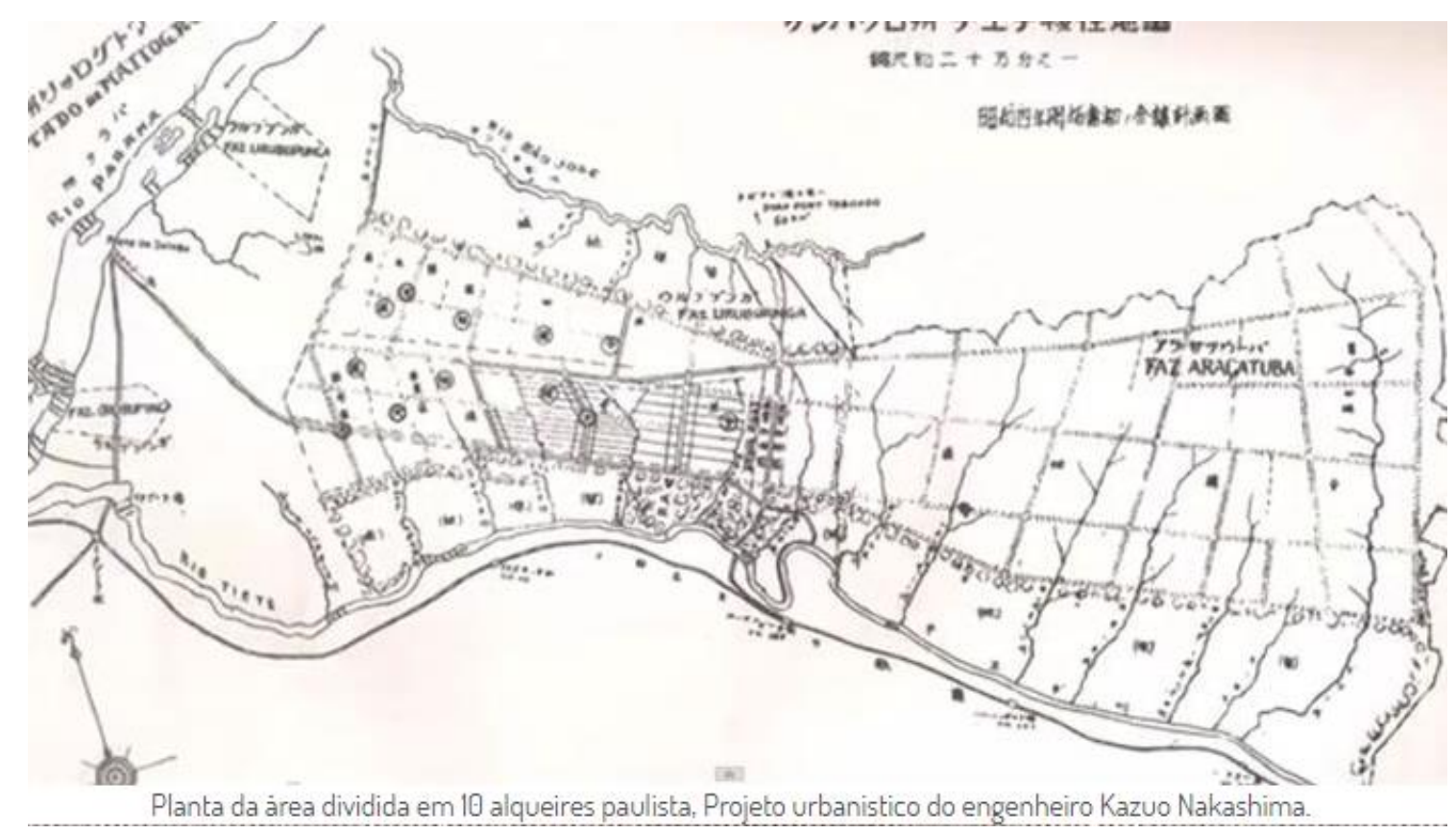

Fonte: Museu da imigração Japonesa na cidade de Pereira Barreto, 2017.

Nos anos de 1928 e 1929, as famílias que compraram as porções de terra desembarcaram no Brasil, após uma longa viagem de 45 dias de navio, onde, já na travessia do oceano, começaram a sofrer com o calor e a alimentação. Os japoneses chegavam ao porto de Santos, e, continuavam sua trajetória de trem até a cidade de São Paulo, onde eram cadastrados na Casa do Imigrante. De lá, seguiam viagem, novamente de trem, até seu destino, apreciando as 


\section{Revista Nacional de}

Gerenciamento de Cidades

fazendas de café que ainda sobreviviam pelo interior do Estado de São Paulo. A condição dada às famílias japonesas era a de que, mesmo tendo adquirido as porções de terra, elas seriam alocadas de acordo com a ordem de chegada ao local. Então, hipoteticamente, a família que chegasse primeiro teria direito à melhor porção de terra. Em todas as porções de terra havia um veio de água, porém, nem sempre com acesso fácil.

As famílias que chegavam estavam em total estado de vulnerabilidade social e ambiental, pois além de encontrarem grandes dificuldades para se acomodarem na nova terra, deveriam se adaptar ao calor intenso, à falta de estrutura para atendimento das necessidades básicas, como alimentação, moradia e transporte. As doenças, como a malária, foram a maior causa de baixa de japoneses na região.

Os japoneses vieram para a região oeste do Estado de São Paulo, no Brasil, fisgados pela possibilidade de enriquecimento devido às plantações de café, conhecidas como "ouro em pó". Algumas famílias ainda se aventuraram no plantio do café, mas, devido à forte geada ocorrida em 1930 na região, onde toda a produção foi danificada, os colonizadores resolveram canalizar seus esforços na plantação de algodão, na pecuária e na mineração. A extração de grandes porções de argila iria abastecer as indústrias de cerâmica da região. Essas atividades consistiram na fonte de renda prioritária até meados de 1989.

A cidade desenvolveu-se ao longo da margem esquerda do Rio Tietê e, pelo fato da estação ferroviária de Lussanvira estar localizada na margem direita, foi necessária à construção de uma ponte para a ligação dos dois lados: a ponte Novo Oriente. A ponte começou a ser construída em 1932, mas, devido à Revolução Constitucionalista, a mesma só pode ser inaugurada em 1935. (Figura 2) 




Fonte: Museu de Imigração Japonesa na cidade de Pereira Barreto, 2018.

Segundo Costa (2006) o rio trazia o sentido de maleabilidade na paisagem urbana. Já NorbergSchulz (2006) argumenta que quando a intervenção humana, no processo de construção, revela e valoriza ainda mais os atributos e os significados da paisagem, tornando-os visíveis, o habitar e construir se tornam um, onde cada um tem suas especificidades e coexiste sem afetar o outro. E foi o que aconteceu após a construção da ponte, pessoas, transportes, paisagem e rio coexistiam sem que um interferisse com o outro.

No entanto os moradores e a região onde está localizada a cidade de Pereira Barreto ficaram vulneráveis à intervenção social e ambiental, além da intervenção política. A região do Baixo Tietê era muito cobiçada e valorizada por conta de seus desníveis, pois com investimentos, os mesmos se tornariam consideráveis fontes de energia com a construção das hidrelétricas. Nessa região já havia sido construída hidrelétrica de llha Solteira, mas a mesma ficava impossibilitada de acionar suas turbinas na época de estiagem. Portanto, foi definido que seria necessária a construção de uma nova hidrelétrica - a de Três Irmãos - localizada na região onde ficava a cidade de Pereira Barreto, para que a água represada do rio Tietê, pudesse suprir a demanda de água no acionamento das turbinas da hidrelétrica vizinha, na época da estiagem. Segundo informações obtidas pelo senhor Sérgio Massuda, presidente do Museu da Cultura Japonesa, as águas do Tietê seriam enviadas para o rio Paraná para que enchessem a represa de Ilha Solteira, possibilitando assim, o funcionamento das turbinas, por intermédio de um canal que faria a ligação entre as duas represas: o canal Pereira Barreto. Também foi 


\section{Revista Nacional de}

Gerenciamento de Cidades

informado pelo senhor Sérgio Massuda que à partir de 11 de agosto de 1990, iniciou-se a inundação das terras férteis da cidade de Pereira Barreto, com o fechamento da barragem da hidrelétrica Três Irmãos.Além de lotes residenciais, parte da cidade, pastos e até mesmo a ponte Novo Oriente - que foi um marco na região, doada pela colônia Japonesa - foi submersa (e repousa sob uma coluna de água de 16 metros, além do ápice de sua abóboda).

Tudo mudou: o desenho da cidade, a paisagem, o clima, a fauna, a flora e a forma de subsistência. A cidade alterou sua característica agrícola, pecuarista e mineradora, passando a ser uma estância de pesca e polo turístico.

Novamente as pessoas precisaram se adaptar, com resiliência, à nova realidade local.

\section{3- VULNERABILIDADE E ADAPTAÇÃO}

O conceito de vulnerabilidade tem despertado o interesse em diversas áreas do conhecimento. No que diz respeito à área ambiental, existe uma ausência de consenso entre os conceitos de risco e vulnerabilidade, dificultando o pleno entendimento do uso dos termos nos casos em que se aplicam.

A vulnerabilidade ambiental pode ser definida como o grau em que um sistema natural é suscetível ou incapaz de lidar com os efeitos das interações externas. Pode ser decorrente de características ambientais naturais ou de pressão causada por atividade antrópica; ou ainda de sistemas frágeis, de baixa resiliência, isto é, com baixa capacidade em retornar ao estado natural de excelência, superando uma situação crítica.

Tricart (1977) define um sistema como um conjunto de fenômenos que se processam mediante fluxos de matéria e energia. Esses fluxos originam relações de dependência mútua entre os fenômenos, originando uma entidade global nova, mais dinâmica (unidade eco dinâmica). Esse conceito permite adotar uma atitude dialética entre a necessidade de análise e a necessidade de uma visão de conjunto, capaz de uma análise de atuação eficaz sobre esse meio ambiente.

Ao tratar de vulnerabilidade ambiental, Santos (2007) define sistemas como um conjunto de elementos que mantém relações entre si e onde residem os seres vivos. Elementos como solo, recursos hídricos, vegetação, campos agrícolas, são estruturas do meio que se relacionam através de fluxos e ciclos. Ao ocorrer uma perturbação no equilíbrio desses sistemas, as relações do meio podem ser bastante diferentes, considerando as características locais naturais e da ocupação humana.

Na questão da vulnerabilidade ambiental também devemos considerar a resiliência e a persistência do sistema. Persistência corresponde à medida de quanto um sistema quando perturbado se afasta do seu equilíbrio ou estabilidade, sem mudar essencialmente seu estado. Neste contexto e em uma abordagem mais recente, Figueiredo (2010) conceitua como vulnerabilidade ambiental a suscetibilidade de um sistema à degradação ambiental, considerando: 


\section{Revista Nacional de}

Gerenciamento de Cidades

- a exposição do sistema às pressões ambientais típicas de atividades agroindustriais, avaliada por indicadores que mostram a pressão antropogênica exercida no sistema;

- a sensibilidade do sistema às pressões exercidas, avaliada pelo uso de indicadores que mostram as características do meio físico e biótico, próprias de uma região (tipo de solo, clima, vegetação) que já ocorrem antes de qualquer perturbação e que interagem com as pressões;

- a capacidade de resposta do meio, avaliada pela adoção de ações de conservação ou preservação ambiental que reduzem os possíveis efeitos das pressões exercidas.

Assim sendo, são as características e magnitudes de interações ao qual um sistema está exposto, que ditam a vulnerabilidade ambiental deste sistema.

Este ensaio considera a resiliência, adaptação e vulnerabilidade, como um trinômio, sendo que o conceito como um todo, teve início com a ecologia entre as décadas de 1960 e 1970 com os estudos dos sistemas ecológicos e suas respostas funcionais a distúrbios e mudanças de regime em contraponto à teoria da estabilidade ecológica (HOLLING,1973; FOLKE, 2006). Esta definição ramificou-se, transformando-se e sendo completada ao longo dos anos, ainda guardando diferenças em seu significado, dependendo do campo disciplinar na qual é aplicada.

No início do século XXI, essa definição passou a ser utilizada em outras esferas de saberes, como por exemplo, nas ciências sociais, na engenharia de previsão a desastres, na arquitetura da paisagem e na ecologia urbana.

Como as definições passaram a considerar as habilidades de reorganização e recuperação para além da capacidade de resistir às ameaças, impactos e perturbações, as mesmas definições passaram a se referir aos sistemas socioecológicos e socioambientais.

Em síntese, vários autores chegaram a uma definição expandida sobre resiliência, podendo defini-la como a capacidade adaptativa de um sistema para absorver ameaças e impactos, reorganizar-se e recuperar-se em face às transformações e mudanças de regime, mantendo sua estrutura básica, funções e identidade (HOLLING, 1973; FOLKE, 2006; WALKER \& SALT, 2006; AHERN,2011; EHRLICH et al., 2012)

Nesse sentido, com o alargamento da calha do rio Tietê após a criação da barragem, podemos observar na Figura 3, a necessidade de adaptação dos moradores da região. 


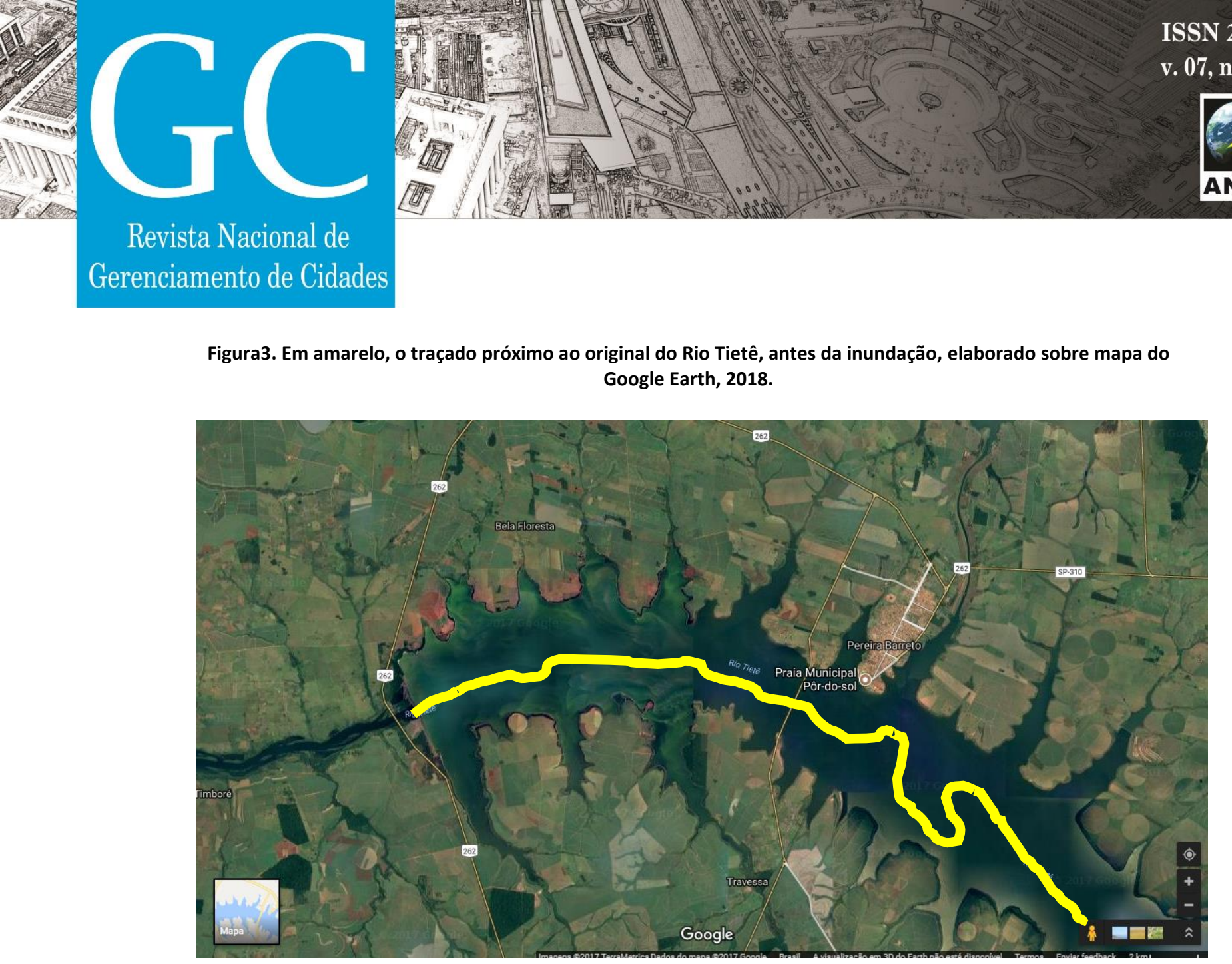

Fonte: Intervenção da Autora, 2018.

\section{4- CONSIDERAÇÕES FINAIS}

Pode-se observar que tanto a paisagem, quanto a população de Pereira Barreto-SP utilizou da resiliência desde o momento da colonização Japonesa pois - em estado de vulnerabilidade - os imigrantes precisaram se adaptar a todas as condições adversas e mesmo que, por imposição e sem informação sobre as consequências de todas as intervenções que passariam na cidade, retomaram seu cotidiano e reescreveram suas memórias.

Hoje a população mais antiga, descendente dos primeiros imigrantes, após a readaptação às novas formas de morar, trabalhar e transitar pela cidade, conta com saudosismo nas rodas de amigos, as peripécias que ocorreram na época da Ponte Novo Oriente, onde a prainha reunia vários grupos de familiares para apreciar o nascer e pôr do Sol, às margens da nova terra do "sol nascente".

\section{REFERÊNCIAS}

AHERN, J. Urban Landscape sustainability and resilience. Landscape Ecology, July 2013, Volume 28, Issue 6, pp 1203-1212. 


\section{Revista Nacional de}

\section{Gerenciamento de Cidades}

BUSS, P.M. Promoção da saúde e qualidade de vida. Ciência e Saúde Coletiva, Rio de Janeiro, v. 5, n.1 , p 163-177, 2000.

COSTA, M. S. A.. Rios e paisagens urbanas em cidades brasileiras. Rio de Janeiro: Prourb, 2006, p. 9-15.

EHRLICH, P. R.; KAREIVA, P. M., DAILY, G. C. Securing natural capital and expending equity to rescale civilization. Nature, 486, p.68-70, 2012.

FIGUEIREDO, M.C.B. (org.) Análise da vulnerabilidade ambiental. Fortaleza: Embrapa Agroindústria Tropical, 2010.

FOLKE,C. Resilience: The emergence of a perspective for social-ecological systems analyses. Global Environmental Change, 16, 2016, p. $253-267$.

GALLO, D. Desenvolvimento sustentável e qualidade de vida: reflexões sobre vulnerabilidade e resiliência urbana. Fórum Ambiental da Alta Paulista, v.13, n.02, p. 44-56, 2017.

HOLLING, C. S. Resilience and stability of ecological systems. Annual Review of Ecology and Systematics, 4, p. 1-23, 1973.

NORBERG-SCHULZ, C. O fenômeno do lugar. In: NESBITT, K. (Org.). Uma nova agenda para a arquitetura. São Paulo: Cosac Naify, 2006. p.444-461

PISANI, M. A. J.; LIMA, F. M.A. . Worshop Arquitetura em Climas Tropicais, 2017.

SANTOS, R. F. (org.) Vulnerabilidade Ambiental desastres naturais ou fenômenos induzidos. Brasília: MMA, 2007.

TRICART, J. Ecodinâmica. Rio de Janeiro: IBGE/SUPREN, 1977.

WALKER, B.; SALT, D. Resilience Thinking: sustaining ecosystems and people in a changing world. Washington DC: Island Press, 2006. 